\title{
The safety, efficacy, and durability of lung-volume reduction surgery: A 10-year experience
}

\author{
Mark E. Ginsburg, MD, ${ }^{a}$ Byron M. Thomashow, MD, ${ }^{b}$ William A. Bulman, MD, ${ }^{b}$ Patricia A. Jellen, MSN, ${ }^{c}$ \\ Beth A. Whippo, MSN, ${ }^{\mathrm{c}}$ Cody Chiuzan, PhD, ${ }^{\mathrm{d}}$ Shing Lee, PhD, ${ }^{\mathrm{d}}$ Dan Bai, MS, ${ }^{\mathrm{d}}$ and Joshua Sonett, $\mathrm{MD}^{\mathrm{a}}$
}

\section{ABSTRACT}

Objectives: The National Emphysema Treatment Trial (NETT) validated the efficacy of lung-volume reduction surgery (LVRS) in selected patients with emphysema; however, concerns about the safety and durability of the operation have limited its clinical application. We evaluated our experience with LVRS, for the time period since approval was given by the Centers for Medicare and Medicaid Services, with respect to surgical morbidity and mortality, early and late functional outcomes, and long-term survival.

Methods: Retrospective analysis was performed on 91 patients for whom consent was obtained for bilateral LVRS at our institution between January 2004 and June 2014. Primary outcomes analyzed were 6-month surgical mortality and overall survival at 1,2, and 5 years. Secondary outcomes (forced expiratory volume in 1 second $\left[\mathrm{FEV}_{1}\right]$, residual volume, carbon monoxide diffusing capacity, a 6minute walk test, exercise capacity, and a shortness-of-breath questionnaire) were analyzed for mean change from baseline at 1, 2, and 5 years after LVRS.

Results: The 6-month surgical mortality rate was $0 \%$. At the 1- and 5-year follow-up, $69 \%$ and $36 \%$ of the patients had an improvement in $\mathrm{FEV}_{1}$. The 1-, 2-, and 5-year $\mathrm{FEV}_{1}$ change in \% predicted of the $\mathrm{FEV}_{1}$, compared with baseline after LVRS, respectively, was 11.1\% (95\% CI: 8.6\%, 13.6\%); 8.7\% (95\% CI: $6.1 \%, 11.4 \%)$; and $11.1 \%(95 \%$ CI: $7.1 \%, 15.0 \%)$; and the maximal workload (in watts [W]) had an average increase of: $10.7 \mathrm{~W}$ (95\% CI: 6.9, 14.6); $7.6 \mathrm{~W}$ (95\% CI: 2.8, 12.4); and 10.24 W (95\% CI: 4.4, 16.1). Overall survival (95\% CI) for the group was: $0.99(95 \% \mathrm{CI}: 0.96,1.00)$ at 1 year; $0.97(95 \% \mathrm{CI}$ : $0.93,1.00)$ at 2 years; and $0.78(95 \% \mathrm{CI}: 0.67,0.89)$ at 5 years.

Conclusions: Given proper patient selection, LVRS is a safe operation. Early functional measurements are consistent with significant clinical benefit. Longterm results demonstrate that improvements can be durable. Surgical LVRS continues to represent the standard for lung-volume reduction therapy. (J Thorac Cardiovasc Surg 2016;151:717-24)

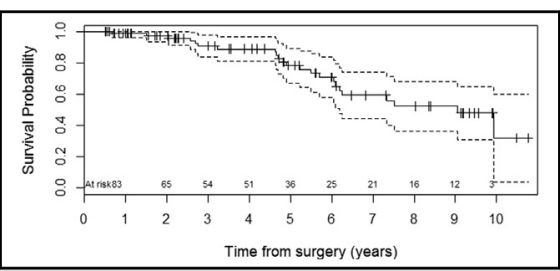

Kaplan-Meier survival curve.

\section{Central Message}

Lung-volume reduction surgery is a safe operation, given proper patient selection. Long-term results demonstrate that improvements can be durable.

\section{Perspective}

In an evaluation of our 10-year experience with LVRS, the 6-month mortality was $0 \%$. At the 1 - and 5 -year follow-up visits, $69 \%$ and $36 \%$ of the patients showed improvement in $\mathrm{FEV}_{1}$. Survival probability was 0.99 (95\% CI: 0.96 , $1.00)$ at 1 year, and $0.78(0.67,0.89)$ at 5 years LVRS is a safe and effective operation, and long-term results demonstrate that functional improvements can be durable.

See Editorial Commentary page 725

See Editorials page 626 and 629.

\section{Supplemental material is available online.}

\footnotetext{
From the ${ }^{a}$ Department of Surgery and ${ }^{b}$ Pulmonary Department of Medicine, Columbia University Medical Center; ${ }^{\mathrm{c}} \mathrm{New}$ York Presbyterian Hospital; and ${ }^{\mathrm{d}}$ Department of Biostatistics, Mailman School of Public Health, Columbia University, New York, NY.

Read at the 95th Annual Meeting of The American Association for Thoracic Surgery, Seattle, Washington, April 25-29, 2015.

Received for publication May 1, 2015; revisions received Oct 16, 2015; accepted for publication Oct 22, 2015; available ahead of print Dec 6, 2015

Address for reprints: Mark E. Ginsburg, MD, Columbia University Medical Center, 161 Fort Washington Ave, New York, NY 10032 (E-mail: meg18@cumc. columbia.edu).

$0022-5223 / \$ 36.00$

Copyright (c) 2016 by The American Association for Thoracic Surgery

http://dx.doi.org/10.1016/j.jtcvs.2015.10.095
}

The National Emphysema Treatment Trial (NETT) demonstrated that lung-volume reduction surgery (LVRS) could improve lung function and survival in patients who have certain defined clinical characteristics. Further analysis of the NETT data showed persistent improvement in survival in surgically treated patients, compared with medically treated patients. ${ }^{2}$ Despite these results, adoption of LVRS in the United States for the treatment of severe emphysema has been exceedingly poor. A review of the Society of Thoracic Surgeons database identified only 538 such surgeries reported during an 8-year period. ${ }^{3}$ Possible reasons for this low level of adoption of LVRS include the following misperceptions: it carries a high risk of surgical morbidity and mortality; it requires an open surgical approach; it has poorly defined 


\section{Abbreviations and Acronyms \\ CI = confidence interval \\ CMS $=$ Centers for Medicare and Medicaid Services \\ COPD $=$ chronic obstructive pulmonary disease \\ DLCO $=$ diffusion capacity of the lungs for carbon monoxide \\ $\mathrm{FEV}_{1}=$ forced expiratory volume in 1 second \\ GI $=$ gastrointestinal \\ GOLD $=$ Global Initiative for Chronic Obstructive Lung Disease \\ ICU = intensive care unit \\ IQR = interquartile range \\ LVRS = lung-volume reduction surgery \\ NETT $=$ National Emphysema Treatment Trial \\ $\mathrm{PaCO}_{2}=$ partial pressure of carbon dioxide \\ $\mathrm{PaO}_{2}=$ partial pressure of oxygen \\ $\mathrm{RV}=$ residual volume \\ SOBQ $=$ University of California San Diego \\ Shortness-of-Breath Questionnaire \\ $\mathrm{W}=$ watts}

selection criteria; and any functional improvement is lacking in durability.

In addition, the persistent hope for less-invasive bronchoscopic alternatives has undoubtedly delayed the use of a surgical intervention in many patients. Since the Centers for Medicare and Medicaid Services (CMS) released the National Coverage Determination ${ }^{4}$ for LVRS in November 2003, we have continued to actively perform LVRS at our institution, and our approach and experience have continued to evolve. Our study is designed to address specifically the issues of surgical safety, clinical efficacy, and functional durability. This report details our clinical results since the time at which CMS approved the procedure, and defines our current surgical management approach.

\section{METHODS}

All patients referred for LVRS underwent full functional and radiologic evaluation, which included pulmonary function testing with plethysmography, a high-resolution computed tomography scan, a quantitative perfusion scan, a 6-minute walk test, a cardiopulmonary exercise test, a cardiac stress test, an echocardiogram, and administration of the University of California San Diego Shortness-of-Breath Questionnaire (SOBQ). ${ }^{5}$ All patients were evaluated by thoracic surgeons who met the CMS and Joint Commission on Accreditation of Healthcare Organizations standard of eligibility ${ }^{6}$ for performing LVRS, and by experienced LVRS pulmonologists and nurses.

The medical management of the emphysema patients was maximized according to the GOLD (Global Initiative for Chronic Obstructive Lung Disease) guidelines ${ }^{7}$; accordingly, all patients were enrolled in a 6- to 8week pulmonary rehabilitation program. Upon completion of the pulmonary rehabilitation program, reassessment (at minimum, a 6-minute walk and cardiopulmonary exercise test) of the patient was performed to ascertain the appropriateness of LVRS at that time. At bimonthly, interdisciplinary LVRS team meetings, all potential LVRS candidates were presented and discussed in relation to the appropriateness of surgical intervention. Surgical candidates were selected according to CMS inclusion and exclusion criteria, ${ }^{4}$ and all patients were either NETT group 1 (upper-lobe predominant, low exercise) or 2 (upper-lobe predominant, high exercise). Approximately $15 \%$ of the patients who were referred for consideration were offered and accepted LVRS.

Consent was obtained for all surgical patients for inclusion in the LVRS Clinical Registry, which was approved by the institutional review board, and data were collected prospectively. Retrospective analysis was performed on 91 patients who provided consent for bilateral LVRS at our institution between January 2004 and June 2014. For postoperative LVRS testing, every effort was made to have patients return for follow-up evaluation at 6 months, and annually thereafter. However, distance, cost, and insurance coverage all played a role in patients' willingness and ability to return for follow-up.

The primary outcomes analyzed included 6-month surgical mortality and morbidity; and overall survival at 1, 2, and 5 years. Secondary outcomes included postbronchodilator forced expiratory volume in 1 second $\left(\mathrm{FEV}_{1}\right)$, residual volume (RV), diffusion capacity of the lungs for carbon monoxide (DLCO), postrehabilitation 6-minute walk test, postrehabilitation exercise capacity (maximal workload), and postrehabilitation SOBQ total score. Baseline pulmonary function testing $\left(\mathrm{FEV}_{1}, \mathrm{RV}\right.$, and DLCO) was reported before rehabilitation, unless the patient's clinical status warranted repeat testing; then postrehabilitation was reported. Results of the 6-minute walk test and exercise capacity were reported from testing performed after rehabilitation. These outcomes were analyzed as the mean absolute change from baseline at 1,2, and 5 years after LVRS. All patients had upper lobe-predominant emphysema, as assessed by high-resolution computed tomography (see Table 1 for baseline characteristics).

\section{Statistical Analysis}

Descriptive statistics were used to summarize patient characteristics: mean and $\mathrm{SD}$, or median and interquartile range (IQR) for continuous variables; frequency and percentages for categoric variables. The percentages of patients with various categories of changes for $\mathrm{FEV}_{1}$, maximum exercise capacity, 6-minute walk test, and questionnaire score were calculated, along with the percentage of patients who had improvement in each outcome. For these analyses, all patients who were eligible for follow-up were included in the analysis; patients who did not return were assumed to have the second-worst category and thus were considered to have deteriorated in their functional outcomes.

Follow-up visit time points (range) were at: 6 months (3-9 months); 1 year (10-18 months); 2 years (19-30 months); and 5 years (49-72 months). At each of these 3 time points, patients were considered eligible if they reached the upper bound of the follow-up window at the date of the data lock. For example, only patients who had 18 months of follow-up as of July 23, 2014 were included in the 1-year analysis (no changes or additions to data were allowed after July 23, 2014). For data for the patients who returned for follow-up, 2-sided, paired $t$ tests were employed to compare functional outcomes for each individual at 1,2 , and 5 years with their baseline.

Additionally, longitudinal analyses using linear mixed-effects models were conducted to assess the relationships between the absolute changes from baseline in 3 main functional outcomes $\left(\mathrm{FEV}_{1}\right.$ percentage predicted, maximal workload, questionnaire score) and the actual follow-up times (years). The models included a fixed effect for "time" (linear term), and a residual random component to account for within-subject correlation. Visual inspection of residual plots did not reveal any obvious deviations from homoscedasticity or normality; therefore, no transformation of the "time" variable was required.

Survival estimates, along with a $95 \%$ confidence interval, were computed using the Kaplan-Meier method. All analyses used a type I error, set at 0.05, and were performed in SAS version 9.4 (SAS Institute, Cary, NC). 
TABLE 1. Baseline characteristics

\begin{tabular}{|c|c|}
\hline Preoperative characteristics & Statistics $(n=91)$ \\
\hline Age (y) & $62.5 \pm 6.3$ \\
\hline Body mass index $\left(\mathrm{kg} / \mathrm{m}^{2}\right)$ & $25.2 \pm 3.8$ \\
\hline \multicolumn{2}{|l|}{ Race } \\
\hline White & $82(90.1)$ \\
\hline Hispanic and black & $9(9.9)$ \\
\hline Gender, male & $38(41.8)$ \\
\hline \multicolumn{2}{|c|}{ Distribution of emphysema on chest tomography scan } \\
\hline Predominantly upper lobe & $91(100)$ \\
\hline Maximal workload (W) & $37.6 \pm 19.9$ \\
\hline 6-min walking test (ft.) & $1248.1 \pm 263.6$ \\
\hline \multicolumn{2}{|l|}{$\mathrm{FEV}_{1}$ after bronchodilator use } \\
\hline$\%$ of predicted value & $25.8 \pm 6.2$ \\
\hline Absolute value & $0.7 \pm 0.2$ \\
\hline Residual volume ( $\%$ of predicted value) & $214.0 \pm 42.0$ \\
\hline DLCO ( $\%$ of predicted value $)$ & $28.6 \pm 7.2$ \\
\hline $\mathrm{PaCO}_{2}(\mathrm{~mm} \mathrm{Hg})$ & $40.2 \pm 6.5$ \\
\hline $\mathrm{PaO}_{2}(\mathrm{~mm} \mathrm{Hg})$ & $67.4 \pm 9.6$ \\
\hline \multicolumn{2}{|l|}{ Type of surgery } \\
\hline Bilateral VATS & $78(85.7)$ \\
\hline Median sternotomy & $11(12.1)$ \\
\hline Right VATS & $2(2.2)$ \\
\hline Total SOBQ score & $61.1 \pm 18.2$ \\
\hline
\end{tabular}

Values are $\mathrm{n}(\%)$, or mean $\pm \mathrm{SD}$, unless otherwise indicated. $W$, Watts; $F E V_{l}$, forced expiratory volume in 1 second; $D L C O$, diffusing capacity of the lungs for carbon monoxide; $\mathrm{PaCO}_{2}$, partial pressure of carbon dioxide; $\mathrm{PaO}_{2}$, partial pressure of oxygen; VATS, video-assisted thoracic surgery; $S O B Q$, University of California San Diego Shortness-of-Breath Questionnaire.

\section{Surgical Approach}

The surgical approach before 2005 was either trans-sternal, bilateral LVRS, or bilateral video-assisted thoracic surgery LVRS. Starting in 2005, all patients were approached using bilateral, video-assisted thoracic surgery LVRS. Targeted lung tissue for resection was chosen based on preoperative radiologic assessment and intraoperative findings of air trapping and perfusion. Approximately $25 \%$ to $35 \%$ of lung volume was removed from each hemithorax. Staple-line reinforcement was routinely used, and patients were scheduled for extubation at the completion of the procedure. Chest-tube management was individualized, but control of the pleural space was obtained with the minimal amount of chest-tube suction deemed necessary. Persistent air leaks lasting $>5$ days were managed by conversion of the chest-drainage system to a Heimlich valve, and the patient was subsequently managed as an outpatient.

\section{RESULTS}

Ninety-one patients underwent LVRS at our institution between 2004 and 2014. The surgical approach was by sternotomy in $11(12 \%)$ patients, bilateral video-assisted thoracic surgery in $78(86 \%)$, and right, video-assisted thoracic surgery in $2(2 \%)$ patients. Two surgeries were limited to a unilateral procedure in the operating room, necessitated by severe adhesions. Functional data were collected on patients who decided to return for follow-up; however, mortality data were available for all 91 patients.

\section{Surgical Morbidity and Mortality}

No surgery-related mortality occurred. At 6 months, all patients were at home and had recovered from their surgical intervention. The median length of hospital stay was 8 days (IQR: 6-10 days), and the median length of intensive care unit stay was 2 days (IQR: $1-3$ days). Discharge disposition was directly to home in $82(90 \%)$ patients, to an inpatient rehabilitation facility in $9(10 \%)$ patients who subsequently returned to home. Major surgery-related complications included respiratory failure that necessitated reintubation and/or tracheostomy in 3 patients, all of whom were weaned and decannulated before discharge. Starting in 2010, no patients required postoperative reintubation. Additional complications included a prolonged air leak of $>7$ days in 52 (57\%) patients, reoperation in $3(3 \%)$ patients, cardiac arrhythmia in $4(4 \%)$ patients, and pneumonia in $4(4 \%)$ patients (Table 2).

\section{1-Year Functional Results}

Seventy-eight patients were eligible for the 1-year follow-up visit; 1 patient died; 58 patients returned for the 1-year follow-up visit; and 19 did not. Of the 78 , improvement was shown by $51 \%$ in maximal workload, $69 \%$ in $\mathrm{FEV}_{1}$, and $54 \%$ in questionnaire score. Among those who returned, the mean absolute change in \% predicted of the $\mathrm{FEV}_{1}$, compared with baseline, was $11.1 \%$ (95\% CI: $8.6 \%, 13.6 \%)$, with a corresponding mean relative change of $43 \%$ (95\% CI: $33 \%, 52 \%)$. The $\%$ predicted of the residual volume, and the SOBQ score, improved compared with baseline, with mean changes of $-64.4(95 \% \mathrm{CI}:-72.7,-56.1)$, and -27.4 (95\% CI: $-35.5,-19.4)$, respectively. The DLCO had a mean increase of $5.2 \%(95 \%$ CI: $3.0 \%, 7.3 \%)$; the maximal workload had an average increase of $10.7 \mathrm{~W}$ (95\% CI: 6.9, 14.6); and the 6-minute walking test increased by $128.7 \mathrm{ft}(95 \% \mathrm{CI}: 76.9,180.5)$ (Table 3; Figure 1).

\section{Two-Year Functional Results}

Seventy-two patients were eligible for the 2 year follow-up; 3 died, 41 were assessed, and 28 were missing. Of this total, $32 \%$ showed improvement in maximal workload, $50 \%$ in $\mathrm{FEV}_{1}$, and $42 \%$ in their questionnaire score. A comparison of the patients who return for follow-up, with their own preoperative baseline functional data, showed an increase in the \% predicted of the $\mathrm{FEV}_{1}$ value with a mean absolute change of $8.7 \%$ (95\% CI: $6.1 \%, 11.4 \%)$, which represented a mean improvement of $37 \%$ (95\% CI: $25 \%, 48 \%)$ from their baseline. The mean absolute change in $\%$ predicted of the residual volume decreased $65.3 \%(95 \% \mathrm{CI}$ : $-78.1 \%,-52.6 \%)$; the DLCO increased $6.4(95 \% \mathrm{CI}$ : $1.5,11.3)$; the maximal workload had a mean increase of $7.6 \mathrm{~W}(95 \% \mathrm{CI}: 2.8,12.4)$, and the 6-minute walk test increased by an average of $125.3 \mathrm{ft}$. (95\% CI: $63.5,187)$. The SOBQ score improved, with a decrease of 22.5 (95\% CI: $-31.7,-12.7)$ (Table 3; Figure 1). 
TABLE 2. Six-month surgical outcomes

\begin{tabular}{lc}
\hline \multicolumn{1}{c}{ Surgical outcomes } & n $(\%)$ or median (IQR) \\
\hline 6-mo mortality $(\mathrm{n}=86$ eligible) & $0(0)$ \\
Discharge disposition $(\mathrm{n}=91)$ & $82(90.1)$ \\
Home & $9(9.9)$ \\
Rehabilitation & $2(1,3)$ \\
Length of stay in ICU (d) & $8(6,10)$ \\
Length of stay in the hospital (d) & \\
Complications & $52(57)$ \\
Prolonged air leak (>7 d) & $4(4)$ \\
Pneumonia & $4(4)$ \\
Cardiac arrhythmia & $3(3)$ \\
Respiratory failure/reintubation/tracheostomy & $3(3)$ \\
Reoperation & $3(3)$ \\
Gastrointestinal (bleeding, bowel obstruction) & $2(2)$ \\
Vocal cord injury & $1(1)$ \\
Deep vein thrombosis & $1(1)$ \\
Pulmonary embolism & $1(1)$ \\
Brachial nerve injury &
\end{tabular}

\section{Five-Year Functional Results}

Forty-five patients were eligible for the 5-year follow-up assessment ( 8 died; 18 returned for follow-up and 19 did not). Of this total, $24 \%$ still showed improvement in their maximal workload, compared with baseline, $36 \%$ in their $\mathrm{FEV}_{1}$, and $33 \%$ in their SOBQ score. Eleven patients had a $>10 \%$ absolute increase in their $\%$ predicted $\mathrm{FEV}_{1}$ at the 5-year follow-up visit. Among those who returned, the mean absolute change in $\%$ predicted of the $\mathrm{FEV}_{1}$ increased $11.1 \%$ (95\% CI: $7.1 \%, 15.0 \%)$, which represented a $45 \%$ $(27 \%, 63 \%)$ relative mean improvement compared with their baseline. The mean absolute change in \% predicted of the residual volume decreased $94.3 \%(-109.7 \%$, $-78.8 \%)$; the DLCO increased by an average of $4.1 \%$ $(0.2 \%, 7.9 \%)$; the maximal workload increased $10.24 \mathrm{~W}$ (95\% CI: 4.4, 16.1); and the 6-minute walk test decreased $59.5 \mathrm{ft}$. $(-224.8,105.8)$. The SOBQ score continued to show improvement, with a decrease of $20.5(-37.3,-3.8)$.

\section{Longitudinal Analysis Results}

Table 4 contains the fixed-effects estimates for all 3 mixed models. Figures E1-E3 (Supplementary Materials) show the individual profiles of absolute changes in $\mathrm{FEV}_{1}$ ( $\%$ predicted), maximal workload, and SOBQ score for all (available) follow-up times. Although significant improvement was seen in all 3 functional outcomes, a slight but statistically significant decline occurred over time. For instance, based on the model estimates (Table 4), the estimated mean change in $\mathrm{FEV}_{1}$ (\% predicted) at 1 year was 9.88 , and for every year increase, the mean $\mathrm{FEV}_{1}(\%$ predicted value) decreased by $1.41 \%(95 \% \mathrm{CI}:-1.89$, $-0.92)$. The estimated mean change in maximal workload at 1 year was $9.89 \mathrm{~W}$, with an estimated decrease per year
TABLE 3. Functional outcomes at 1, 2, and 5 years, among those with follow-up assessments

\begin{tabular}{|c|c|c|c|}
\hline Functional outcomes & n & Mean $(95 \%$ CI) & $P$ value \\
\hline \multicolumn{4}{|l|}{1 y $(10-18 \mathrm{mo})$} \\
\hline $\mathrm{FEV}_{1}(\%$ predicted $)$ & 58 & $11.1(8.6,13.6)$ & $<.001$ \\
\hline RV (\% predicted) & 58 & $-64.4(-72.7,-56.1)$ & $<.001$ \\
\hline DLCO $(\%$ predicted $)$ & 58 & $5.2(3.0,7.3)$ & $<.001$ \\
\hline 6-MWT (ft.) & 57 & $128.7(76.9,180.5)$ & $<.001$ \\
\hline Maximal workload (W) & 53 & $10.7(6.9,14.6)$ & $<.001$ \\
\hline SOBQ score & 49 & $-27.4(-35.5,-19.4)$ & $<.001$ \\
\hline \multicolumn{4}{|l|}{2 у (19-30 mo) } \\
\hline $\mathrm{FEV}_{1}(\%$ predicted $)$ & 41 & $8.7(6.1,11.4)$ & $<.001$ \\
\hline RV (\% predicted) & 40 & $-65.3(-78.1,-52.6)$ & $<.001$ \\
\hline DLCO $(\%$ predicted $)$ & 40 & $6.4(1.5,11.3)$ & .012 \\
\hline 6-MWT (ft.) & 40 & $125.3(63.5,187)$ & $<.001$ \\
\hline Maximal workload (W) & 38 & $7.6(2.8,12.4)$ & .003 \\
\hline SOBQ score & 38 & $-22.2(-31.7,-12.7)$ & $<.001$ \\
\hline \multicolumn{4}{|l|}{5 y $(49-72 \mathrm{mo})$} \\
\hline $\mathrm{FEV}_{1}(\%$ predicted $)$ & 18 & $11.1(7.1,15.0)$ & $<.001$ \\
\hline RV (\% predicted) & 18 & $-94.3(-109.7,-78.8)$ & $<.001$ \\
\hline DLCO $(\%$ predicted $)$ & 18 & $4.1(0.2,7.9)$ & .041 \\
\hline 6-MWT (ft.) & 18 & $-59.5(-224.8,105.8)$ & .458 \\
\hline Maximal workload (W) & 17 & $10.24(4.4,16.1)$ & .002 \\
\hline SOBQ score & 19 & $-20.5(-37.3,-3.8)$ & .019 \\
\hline
\end{tabular}

$C I$, Confidence interval; $F E V_{1}$, forced expiratory volume in 1 second; $R V$, residual volume; $D L C O$, diffusing capacity for carbon monoxide; 6-MWT, 6-minute walk test; $W$, watts; $S O B Q$, University of California San Diego Shortness-of-Breath Questionnaire.

of $3.88(95 \%$ CI: $-4.89,-2.87)$. The estimated mean decrease at 1 year in SOBQ score was 29.72 points, with an increase of 3.49 points $(95 \%$ CI: $2.03,4.94)$ per year. These estimates are comparable to our descriptive statistics (Table 3), and therefore, they should be used together.

\section{Survival}

Survival status was available for all patients. Twentythree patients died during the follow-up period, 10 months to 10 years postoperatively. The cause of death was respiratory related in $12(52 \%)$ patients, nonrespiratory in 9 $(39 \%)$, and unknown in $2(9 \%)$. Nonrespiratory causes of death included: lung cancer (3); murder (1); ovarian cancer (1); heart failure (1); uterine cancer (1); shingles (1); and renal failure (1). Additionally, 3 patients underwent lung transplantation for progressive respiratory failure. The 1-, 2-, and 5-year survival estimates $(95 \% \mathrm{CI})$ were: 0.99 (0.96-1.00); 0.97 (0.93-1.00); and 0.78 (0.67-0.89), respectively. The median survival was 9.1 years $(6.2$, infinity) (Figure 2).

\section{DISCUSSION}

Although NETT initially defined a high-risk group of patients who had a low diffusing capacity and diffuse emphysema, and who suffered excess mortality with surgical therapy, ${ }^{8}$ the final NETT results demonstrated that for 
Maximal Workload (W)
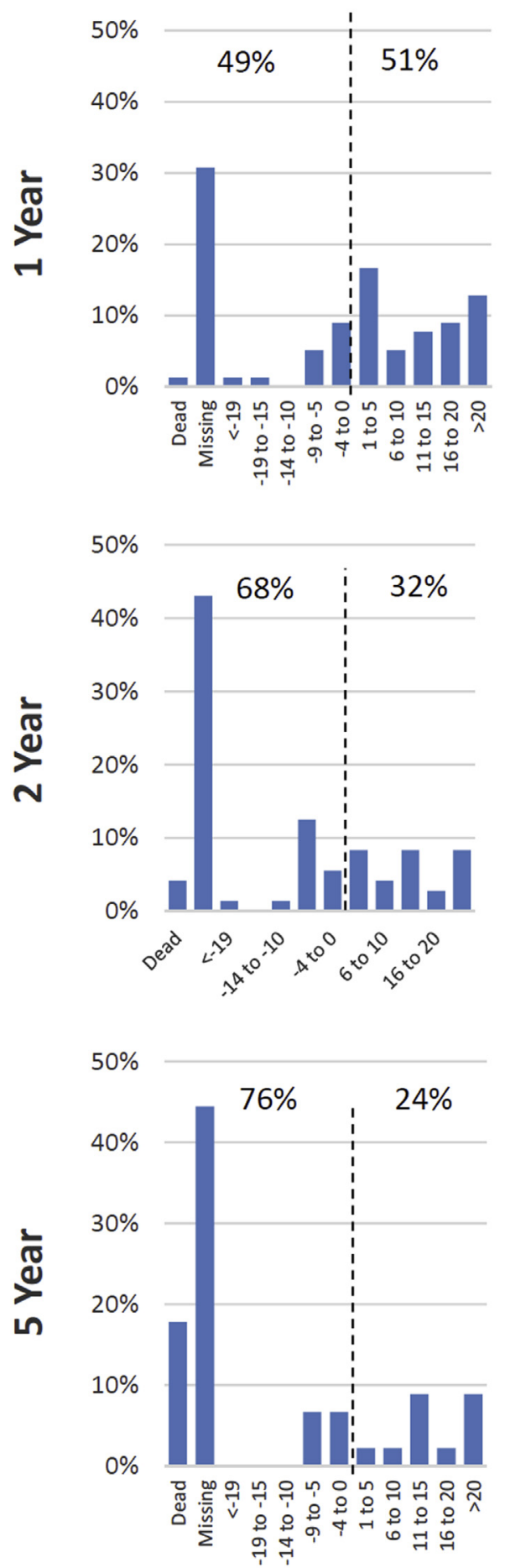

$\mathrm{FEV}_{1}(\%$ Predicted $)$
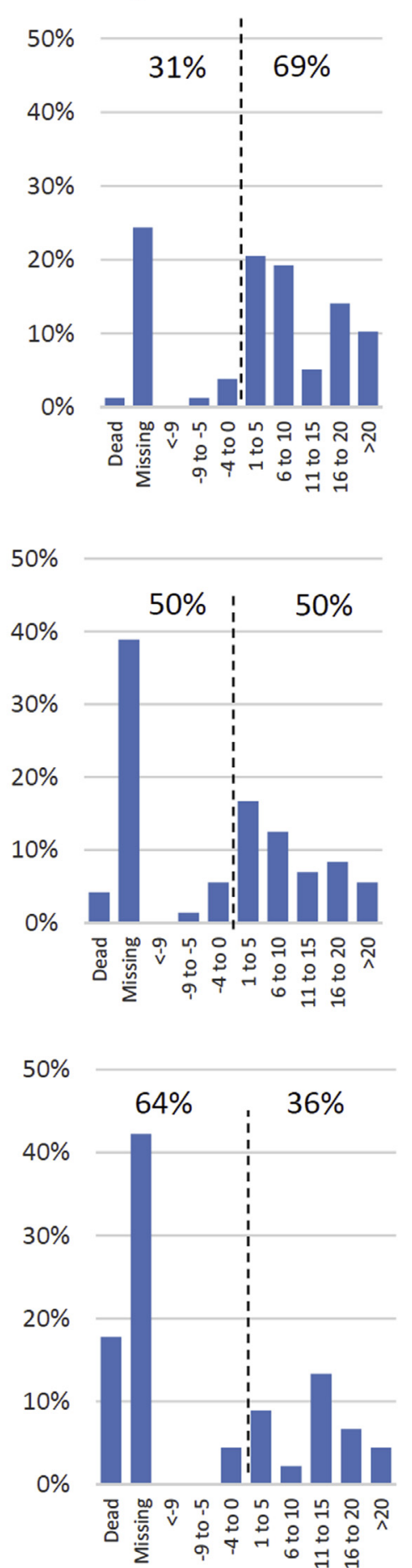

SOBQ
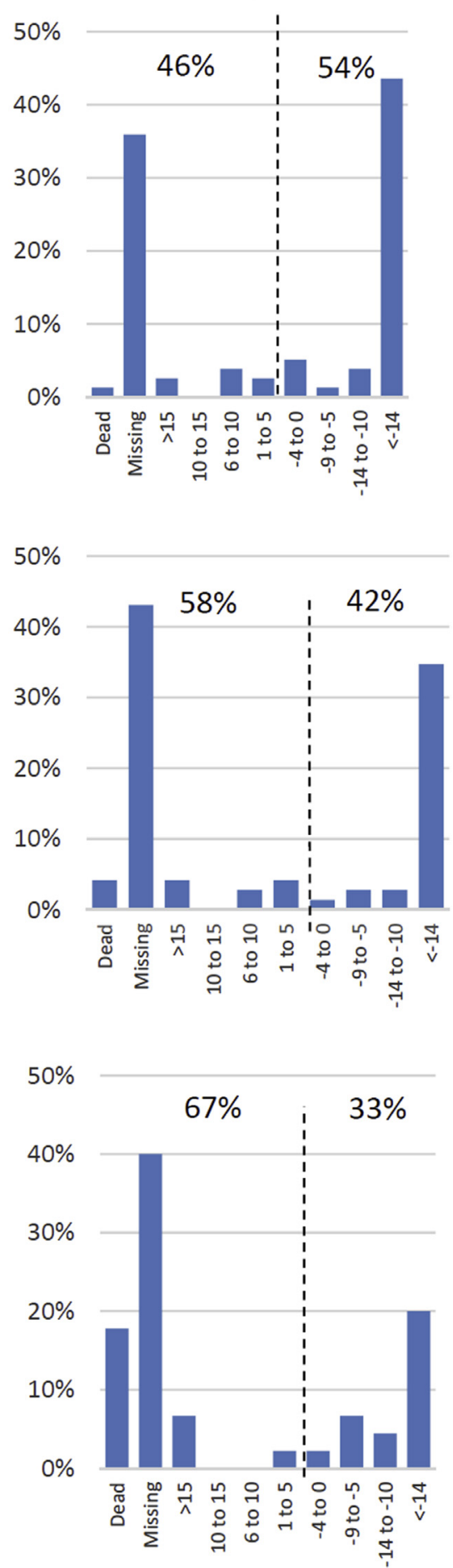

FIGURE 1. Histograms of changes from baseline in exercise capacity, $\mathrm{FEV}_{1} \%$ predicted, and SOBQ score after 1, 2, and 5 years; $y$-axis indicates the percentage of patients; $x$-axis indicates the change from baseline in the corresponding unit (watts, $\%$ predicted, or SOBQ score). $W$, Watts; $F E V_{l}$, forced expiratory volume in 1 second; $S O B Q$, University of California San Diego Shortness-of-Breath Questionnaire.

carefully selected patients who had upper lobe-predominant emphysema, LVRS was able to improve function, exercise capacity, and quality of life. ${ }^{1}$ In addition, the
NETT demonstrated that LVRS, in a selected group of emphysema patients, resulted in a survival advantage compared with medical therapy. ${ }^{2}$ Lung-volume reduction 
TABLE 4. Fixed-effects estimates for modeling absolute changes as a function of time

\begin{tabular}{|c|c|c|c|}
\hline Parameter & Estimate (SE) & $95 \% \mathrm{CI}$ & $P$ value \\
\hline \multicolumn{4}{|c|}{$\mathrm{FEV}_{1}(\%$ predicted value $)$} \\
\hline Intercept & $11.29(1.07)$ & $(9.17,13.42)$ & $<.0001$ \\
\hline Time (y) & $-1.41(0.25)$ & $(-1.89,-0.92)$ & $<.0001$ \\
\hline \multicolumn{4}{|c|}{ Maximal workload (W) } \\
\hline Intercept & $13.77(0.98)$ & $(11.81,15.73)$ & $<.0001$ \\
\hline Time (y) & $-3.88(0.51)$ & $(-4.89,-2.87)$ & $<.0001$ \\
\hline \multicolumn{4}{|l|}{ SOBQ score } \\
\hline Intercept & $-33.21(3.17)$ & $(-39.53,-26.88)$ & $<.0001$ \\
\hline Time $(y)$ & $3.49(0.73)$ & $(2.03,4.94)$ & $<.0001$ \\
\hline
\end{tabular}

$S E$, Standard error; $C I$, confidence interval; $F E V_{l}$, forced expiratory volume in 1 second; $W$, watts; $S O B Q$, University of California San Diego Shortness-of-Breath Questionnaire.

surgery is the first new therapy since use of oxygen was introduced some 40 years earlier to demonstrate an advantage versus medical therapy. ${ }^{9,10}$ The trial was cosponsored by the National Heart, Lung, and Blood Institute and CMS, and LVRS was subsequently approved by CMS at selected centers of excellence, for patients who met the criteria defined by the study.

Only a limited number of these procedures have been performed in the subsequent 10 years. ${ }^{3}$ Possible factors contributing to the low utilization likely include both concern about the high surgical morbidity and mortality seen in the NETT as well as other surgical studies, ${ }^{11}$ and the lack of evidence of durability of functional improvement. We believe our results reinforce the positive outcomes of the NETT with respect to functional improvement, and furthermore demonstrate that those improvements are durable in some patients. Being able to obtain these improvements without any surgical mortality is an added benefit.

The NETT reported a 90-day surgical mortality in nonhigh-risk patients $(\mathrm{n}=538)$ of $5.2 \%$, compared with a 90-day mortality of $1.5 \%$ in comparable medically treated patients. ${ }^{1}$ Among patients with upper lobe-predominant disease, the 90 -day mortality was $2.9 \%$, versus $1.9 \%$ in medically treated patients. Respiratory complications in NETT at 30 days after LVRS were significant for: pneumonia $(18.2 \%)$; reintubation $(21.8 \%)$; tracheostomy $(8.2$ $\%)$; and inability to wean from mechanical ventilation $(8 \%) .{ }^{12}$ In the non-high-risk NETT surgical group, only $69.7 \%$ of postoperative patients were living at home at 30 days after LVRS. ${ }^{13}$ In the 91 cases performed at our center since 2004, we report no 6-month mortality. In contrast to the NETT cohort, only $3 \%$ of our patients developed postoperative respiratory failure that necessitated reintubation, and none since 2010 . A total of $90 \%$ of our patients were living at home at 30 days after LVRS.

Although careful adherence to NETT selection criteria clearly contributed to our low surgical mortality, our 20-year LVRS experience undoubtedly played a role as

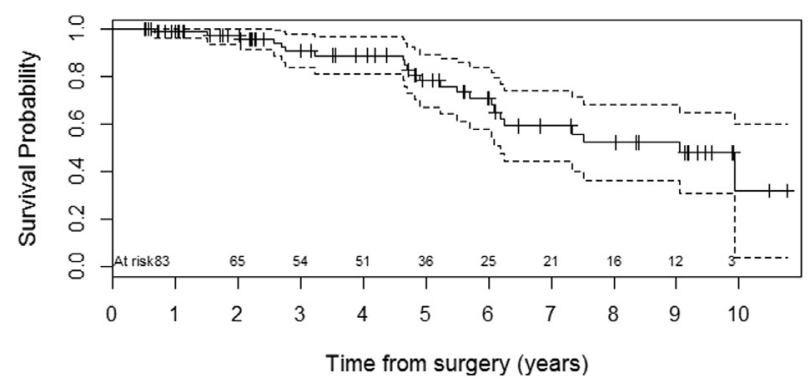

FIGURE 2. Kaplan-Meier survival curve (solid line) with the $95 \%$ confidence interval (dashed line).

well. In addition, although the NETT did not document any significant difference between the median sternotomy and video-assisted thoracic surgery approaches, ${ }^{14}$ the latter was in its infancy during the NETT. Increasing experience with this minimally invasive approach likely contributed to the dramatically reduced postoperative mortality. Prolonged air leaks ( $>7$ days) were the most common complication, occurring in $57 \%$ of patients. However, by using Heimlich valves, we could mobilize patients and expedite their discharge from the hospital. Efficacy, as measured by functional improvements in the first year, showed changes consistent with those found in the NETT and other previous LVRS studies. ${ }^{15-17}$

Possibly, enthusiasm for an FDA-approved bronchoscopic technique to accomplish LVR has caused deferral of patients who are hoping for a less-invasive approach. Numerous clinical trials of multiple bronchoscopic devices have resulted in either clinical failure or lack of meaningful improvement in pulmonary function. ${ }^{18-21}$ At this time, the role of bronchoscopic LVR remains unclear. No bronchoscopic approach to LVR has been approved in the United States, and when comparing the bronchoscopic LVR functional data published to date with our LVRS results, the postsurgical results seem to be far superior. ${ }^{22}$

The issue of durability of LVRS has never been adequately addressed. Although several studies suggest that benefits from LVRS are transient and will decay after the first or second year, the NETT 3-year results show evidence of durability, with significant improvements in lung function, exercise capacity, and relief of dyspnea. ${ }^{2}$ Our experience indicates similar improvements in lung function and exercise capacity at years 1 and 2. Specifically, for upper-lobe patients (low and high exercise capacity), the percentage of patients with significant improvement (>10 watts) in exercise capacity at 2 years was $19 \%$, compared with $21 \%$ in the NETT study.

In addition, at 5 years, $20 \%$ of patients continued to show significant benefit in exercise capacity. Similarly, $24 \%$ of the patients had $\mathrm{a} \geq 10 \%$ absolute increase in $\mathrm{FEV}_{1}$ percentage predicted at the 5-year interval. Of those patients who returned for follow-up at years 1,2 , and 5, a total of 
$40 \%, 37 \%$, and $61 \%$, respectively, had a $\geq 10 \%$ absolute increase in $\mathrm{FEV}_{1}$ percentage predicted, and a $43 \%, 37 \%$, and $53 \%$ significant improvement ( $>10$ watts) in exercise capacity. Most impressive were the improvement in quality-of-life scores, as measured by the questionnaire. At 1,2 , and 5 years, $66 \%, 70 \%$, and $78 \%$, respectively, demonstrated a clinically significant improvement in quality of life (5 points). ${ }^{23}$ Although analysis of our data revealed significant improvement in functional outcomes, these showed a small but statistically significant decrease over time, which is certainly not unexpected, because of both aging and the expected progression of underlying emphysema.

Taking into account deaths and missing data (Figure 1), a significant percentage of patients had sustained improvement. In the 18 patients for whom we have 5-year data, durability was found in functional improvements related to lung function, which suggests that some patients have durable benefits after LVRS. Only the 6-minute walking test was below preoperative values, consistent with an aging population.

The issue of missing data is recognized as a limitation in this report. In an attempt to remove bias from our analysis, we assumed that patients who did not return had experienced deterioration. A similar assumption was made in NETT, and comparison showed that our series had slightly higher rates of improvement at 1 year, and similar rates at 2 years, compared with the surgical group in NETT. Although the rates of improvement at 5 years were lower than those at 2 years, approximately one quarter to one third of the patients still experienced improvement, compared with baseline (Figure 1). Further, emphysema is a progressive disease, and almost all, if not all, emphysema patients experience deterioration in lung function during a 1-, 2-, or 5 -year period, regardless of medical therapies. ${ }^{24}$

The study has additional limitations, including being a single-center study with an extremely experienced group of clinicians. Whether the results can be generalized is impossible to know. The magnitude and geography of surgical resection is still largely an "art" and therefore difficult to describe and teach with precision.

Before the development of CMS criteria defined by the NETT study, the 30-day mortality at our center was $7 \%$. In our 10-year post-NETT series (upper lobe predominant with no differentiation between high and low exercise level), we saw mortality of $1 \%$ mortality at 1 year, $3 \%$ at 2 years, and $22 \%$ at 5 years. This survival pattern was better than that achieved in the best surgical group in NETT (upper lobe/low exercise), but it was even more dramatically improved compared with the survival of those in the matched medical arm of NETT. The best NETT group, those with upper lobe-predominant emphysema and a low baseline exercise level, had an estimated probability of death of approximately $13 \%$ at 1 year, $24 \%$ at 2 years, and $54 \%$ at 5 years in the medical group, compared with an estimated probability of death of $9 \%, 12 \%$, and $36 \%$ in the surgical group. ${ }^{2}$ Only $52 \%$ of our deceased patients died from respiratory failure.

\section{CONCLUSIONS}

Our results clearly show that LVRS can be performed with a negligible risk of mortality and an acceptable low morbidity, using minimally invasive thoracic surgical techniques. The early functional benefit is excellent, and the functional results at 5 years suggest that these improvements are durable, at least in some patients. Late survival for this selected group of patients with advanced emphysema is excellent. Surgical LVRS remains the gold standard against which all other forms of lung-volume reduction must be judged. Surgical LVRS should be offered to a wider range of patients who have advanced emphysema and meet CMS selection criteria.

\section{Conflict of Interest Statement}

Mark E. Ginsburg is a consultant for PneumRx, and has no explicit conflict of interest related to this study. Byron $\mathrm{M}$. Thomashow is Chairman of the Board of COPD Foundation, a nonprofit organization, and has no explicit conflict of interest related to this study. The other authors have nothing to disclose with regard to commercial support.

You can watch a Webcast of this AATS meeting presentation by going to: http://webcast.aats.org/2015/Video/Wednesday/ 04-29-15_608_0731_Ginsburg.mp4.

The LVRS team at New York Presbyterian Hospital/Columbia University Medical Center: Keith Brenner, MD, Angela DiMango, MD, Claire Keating, MD, Roger Maxfield, MD, Wilson Quezada, MD, Chun Yip, MD, Matthew Bacchetta, MD, Frank D’Ovidio, MD, Lyall Gorenstein, MD, Aimee Layton, PhD, the pulmonary diagnostic staff, and the pulmonary rehabilitation staff.

\section{References}

1. National Emphysema Treatment Trial Research Group. A randomized trial comparing lung volume-reduction surgery with medical therapy for severe emphysema. N Engl J Med. 2003;348:2059-73.

2. Naunheim KS, Wood DE, Mohsenifar Z, Sternberg AL, Criner GJ, DeCamp MM, et al. Long-term follow-up of patients receiving LVRS versus medical therapy for severe emphysema by the National Emphysema Treatment Trial Research Group. Ann Thorac Surg. 2006;82:431-43.

3. Decker MR, Leverson GE, Jaoude WA, Maloney JD. Lung volume reduction surgery since the National Emphysema Treatment Trial: study of Society of Thoracic Surgeons database. J Thorac Cardiovasc Surg. 2014;148:2651-8.

4. Centers for Medicare and Medicaid Services (CMS), Department of Health and Human Services (DHHS). CMS Manual System, Publication 100-03, Medicare National Coverage Determinations. Available at: http://www.cms.hhs.gov/ Transmittals/Downloads/R3NCD.pdf. Accessed April 21, 2015.

5. Prewitt LM, Ries AL, Kaplan RM. Validation of a new dyspnea measure. The UCSD shortness of breath questionnaire. Chest. 1998;113:619-24.

6. Joint Commission on the Accreditation of Healthcare Organizations. Disease specific care certification: lung volume reduction surgery (LVRS) certification. Available at: http://www.jointcommission.org/assets/1/18/LVRS_final_addendum \%20.pdf. Accessed April 21, 2015. 
7. Vestbo J, Hurd SS, Agusti AG, Jones PW, Vogelmeier C, Anzueto A, et al. Global strategy for the diagnosis, management, and prevention of chronic obstructive pulmonary disease: GOLD executive summary. Am J Respir Crit Care Med. 2013;187:347-65.

8. National Emphysema Treatment Trial Research Group. Patients at high risk of death after lung volume reduction surgery. N Engl J Med. 2001;345:1075-83.

9. Neff TA, Petty TL. Long-term continuous oxygen therapy in chronic airway obstruction: mortality in relationship to cor pulmonale, hypoxia, and hypercapnia. Ann Intern Med. 1970;72:621-6.

10. Nocturnal Oxygen Therapy Trial Group. Continuous or nocturnal oxygen ther apy in hypoxemic chronic obstructive lung disease: a clinical trial. Ann Intern Med. 1980;93:391-8.

11. Weinmann GG, Hyatt R. NHLBI Workshop Summary: evaluation and research in lung volume reduction surgery. Am J Respir Crit Care Med. 1996;154:1913-6.

12. DeCamp MM, McKenna RJ, Deschamps CC, Krasna M. Lung volume reduction surgery: technique, operative mortality and morbidity. Proc Am Thorac Soc. 2008;5:442-6.

13. Criner GJ, Sternberg AL. National Emphysema Treatment Trial: the major outcomes of lung volume reduction surgery in severe emphysema. Proc Am Thorac Soc. 2008;5:393-405.

14. National Emphysema Treatment Trial Research Group. safety and efficacy of median sternotomy versus video-assisted thoracic surgery for lung volume reduction surgery. J Thorac Cardiovasc Surg. 2004;127:1350-60.

15. Argenziano M, Thomashow B, Jellen PA, Rose EA, Steinglass KM, Ginsburg ME, et al. Functional comparison of unilateral versus bilateral lung volume reduction surgery. Ann Thorac Surg. 1997;64:321-7.

16. Cooper JD, Patterson GA, Sunaresan RS, Trulock EP, Yusen RD, Pohl MS, et al. Results of 150 consecutive lung volume reduction procedures in patients with severe emphysema. J Thorac Cardiovasc Surg. 1996;112:1319-30.

17. Ciccone AM, Myers BF, Guthrie TJ, Davis GE, Yusen RD, Lefrak SS, et al. Long-term outcome of bilateral lung volume reduction in 250 consecutive patients with emphysema. J Thorac Cardiovasc Surg. 2003;125:513-25.

18. Sciurba FC, Ernst A, Herth FJ, Strange C, Criner GJ, Marquette CH, et al. A randomized study of endobronchial valves for advanced emphysema. $N$ Eng J Med. 2010;363:1233-44

19. Deslee G, Klooster K, Hetzel M, Stanzl F, Kessler R, Marquette CH, et al. Lung volume reduction coil treatment for patients with severe emphysema: a European multicenter trial. Thorax. 2014;69:980-6.

20. Slebos DJ, Klooster K, Ernst A, Herth FJ, Kerstjens HA. Bronchoscopic lung volume reduction coli treatment of patients with severe heterogeneous emphysema. Chest. 2012;142:574-82.

21. Kramer MR, Refaely Y, Maimon N, Rosengarten D, Fruchter O. Bilateral endoscopic sealant lung volume reduction therapy for advanced emphysema. Chest. 2012;142:1111-7.

22. Bulman WA, Ginsburg ME, Sonett, J, Yip C, Maxfield R, Jellen P, et al. Effect of prolonged postoperative air leak on outcomes following lung volume reduction surgery. Poster session presented at American Thoracic Society International Conference; 2015 May 15-20; Denver, CO.

23. Kupferberg D, Kaplan R, Slymen D, Ries A. Minimal clinically important difference for the UCSD Shortness of Breath Questionnaire. Cardiopul Rehab. 2005; 25:370-7.

24. Gladysheva ES, Malhotra A, Owens RL. Influencing the decline of lung function in COPD: use of pharmacotherapy. Int J Chron Obstruct Pulmon Dis. 2010;5: 153-64.

Key Words: lung volume reduction surgery, emphysema, chronic obstructive pulmonary disease

\section{Discussion}

Dr R. Cerfolio (Birmingham, Alabama). Mark, Josh, congratulations. This paper should have been in the plenary session, in my opinion. I congratulate you on 91 patients, no mortality, and incredible followup. I have 2 quick questions. One, as surgeons, why are we not trying to sell this approach, meaning promote it to the medical community?
We are not doing that, right? You did 91 in 10 years. That is not very many. I only do a few a year. Tell us why the medical community does not buy it.

Dr Ginsburg. Thank you, Dr Cerfolio, for your thoughtful questions.

In many ways, promoting the benefits of LVRS to the medical community is our own fault. We failed in 2003 the same way Brantigan failed in the 1950s. Our surgical morbidity and mortality was too high. One of the reasons for this is that we tested an operation in NETT that was not a mature operation. We really hadn't worked out all the problems. As surgeons, when we look at NETT, we look at the favorable functional results that we obtained. The surgical patients in the non-high-risk group in NETT clearly did better functionally than the medical patients. That is how we looked at it. How did the medical professionals look at it? They looked at the surgical complications and mortality. There are some sobering numbers in that. The non-high-risk group had a mortality in excess of 5\%-30\% of the surgical patients required a reintubation within the first 30 days, and $8 \%$ of the surgical patients never came off the ventilator. Those are sobering statistics for a palliative, elective operation.

Dr Cerfolio. I agree. But now you have shown that none of that is true. So how do we get the new message out?

Dr Ginsburg. First, we need to do this operation better, and the only way we are going to do it better is to persistently look at what we have done and try to reduce the complication rate. It is the usual learning curve of what we do. I think the biggest lesson we learned was to resect less than your gut tells you to resect. What hurts these patients is over-resection, pleural space problems, and air leaks. This is the problem, and this is the problem with over-resection. I think that the biggest lesson and the reason that we did better in the next 10 years after NETT is that we backed down on how much we were resecting.

Dr Cerfolio. My second and short last question is missing data. Every time we see these reports, they do not have the kind of data that you guys do. Talk to us about how that is handled by you and getting patients to come back and how you were able to achieve what you did. Congratulations.

\section{Dr Ginsburg. Thank you.}

Missing data are always a problem. If you compare apples to oranges, that is, patients that you actually get follow-up on to the base that you start with, you can distort your results, obviously. It was not a clinical trial. We can only get so many patients back for functional testing. We have $100 \%$ follow-up for survival, which I think is an important number. But we chose to compare the patients that we had functional data on at 1 year and 5 years to their own preoperative baseline data. I think that really says what these patients did. 


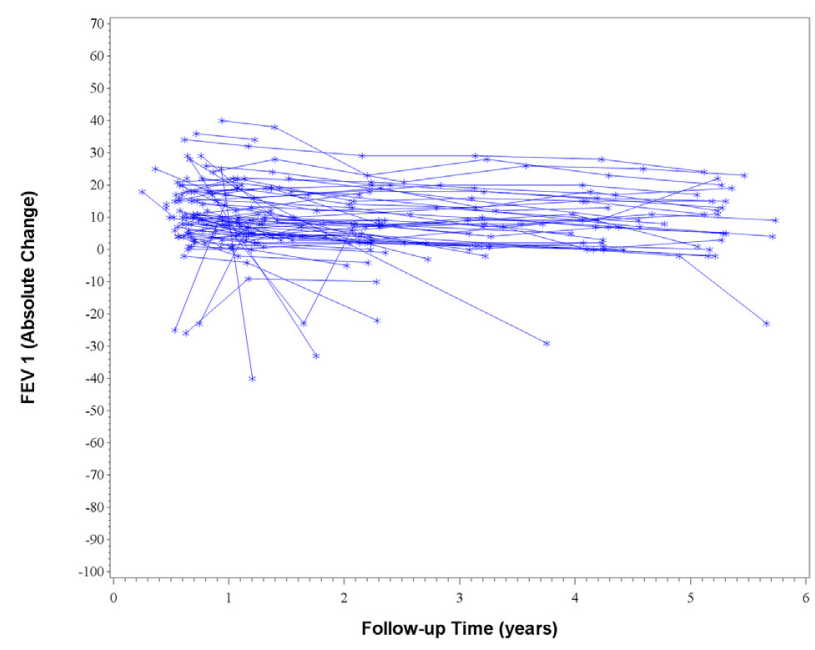

FIGURE E1. Individual profile plots of absolute changes in $\mathrm{FEV}_{1}$ ( $\%$ predicted) over time. $F E V_{1}$, forced expiratory volume in 1 second.

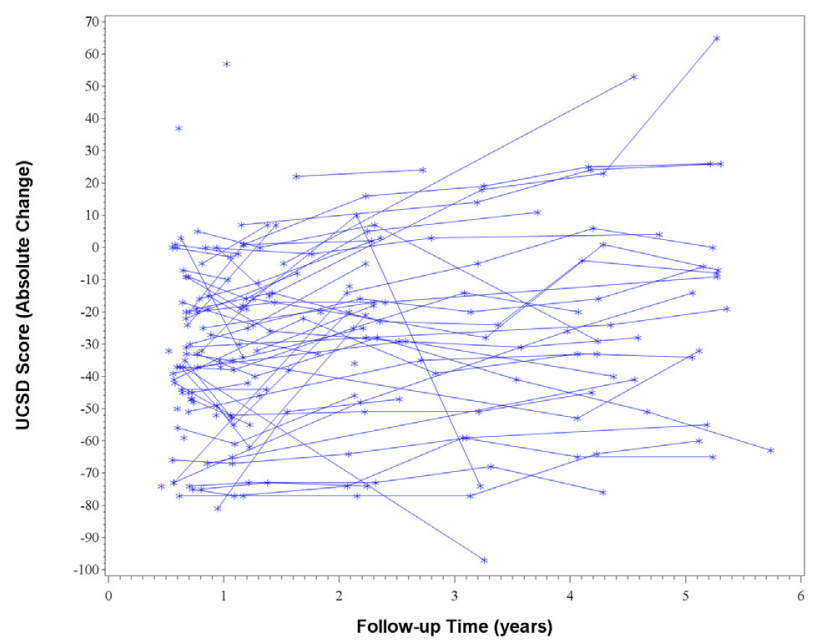

FIGURE E3. Individual profile plots of absolute changes in University of California San Diego SOBQ score over time. SOBQ, University of California San Diego Shortness-of-Breath Questionnaire.

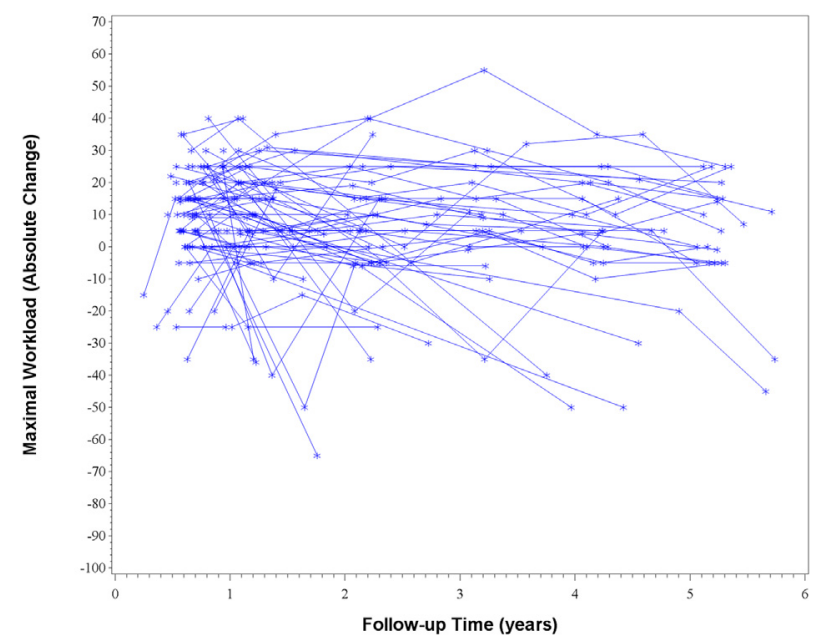

FIGURE E2. Individual profile plots of absolute changes in maximal workload over time. 